University of Nebraska - Lincoln

DigitalCommons@University of Nebraska - Lincoln

Faculty Publications - Textiles, Merchandising and Fashion Design

Textiles, Merchandising and Fashion Design,

Department of

2010

Lightweight Polypropylene Composites Reinforced by Long Switchgrass Stems

\author{
Yi Zou \\ University of Nebraska-Lincoln \\ Helan Xu \\ University of Nebraska-Lincoln, hxu14@unl.edu \\ Yiqi Yang \\ University of Nebraska-Lincoln, yyang2@unl.edu
}

Follow this and additional works at: https://digitalcommons.unl.edu/textiles_facpub

Zou, Yi; Xu, Helan; and Yang, Yiqi, "Lightweight Polypropylene Composites Reinforced by Long Switchgrass Stems" (2010). Faculty Publications - Textiles, Merchandising and Fashion Design. 37. https://digitalcommons.unl.edu/textiles_facpub/37

This Article is brought to you for free and open access by the Textiles, Merchandising and Fashion Design, Department of at DigitalCommons@University of Nebraska - Lincoln. It has been accepted for inclusion in Faculty Publications - Textiles, Merchandising and Fashion Design by an authorized administrator of DigitalCommons@University of Nebraska - Lincoln. 


\title{
Lightweight Polypropylene Composites Reinforced by Long Switchgrass Stems
}

\author{
Yi Zou, ${ }^{1}$ Helan $\mathrm{Xu}^{1}{ }^{1}$ and Yiqi Yang ${ }^{1,2,3}$ \\ 1. Department of Textiles, Clothing and Design, University of Nebraska-Lincoln, 234 HECO Building, \\ Lincoln, NE 68583-0802, USA \\ 2. Department of Biological Systems Engineering, University of Nebraska-Lincoln, Lincoln, NE, USA \\ 3. Nebraska Center for Materials and Nanoscience, University of Nebraska-Lincoln, Lincoln, NE, USA \\ Corresponding author - Yiqi Yang, email yyang2@unl.edu
}

\begin{abstract}
Switchgrass (SG) stems with lengths up to $10 \mathrm{~cm}$ have been used as reinforcement to make lightweight composites with polypropylene (PP) webs. The long SG stems, with simple cut or split and without chemical treatment, were used directly in the composites. Utilizing SG stems for composites not only increases the values of SG but also provides a green, sustainable and biodegradable material for the composites industry. Lightweight composites are preferred, especially for automotive applications due to the potential saving in energy. In this research, the effects of manufacturing parameters on the properties of composites have been studied. Although the tensile properties of SG stem are significantly worse than jute fiber, SG stem with low bulk density is found to better reinforce the lightweight composites. Compared with the jute-PP composites of the same density $\left(0.47 \mathrm{~g} / \mathrm{cm}^{3}\right)$, composites reinforced by the split SG stems have $56 \%$ higher flexural strength, $19 \%$ higher modulus of elasticity, 15\% higher impact resistance, 63\% higher Young's modulus, 52\% lower tensile strength, and similar sound absorption property. The SG-PP composites with optimized properties have the potential to be used for industrial applications such as the support layers in automotive interiors, office panels and ceiling tiles.
\end{abstract}

Keywords: lightweight composites, switchgrass, polypropylene web, renewable resource

\section{Introduction}

This paper reports the properties of the lightweight composites reinforced by SG stems. Compared with the conventional compact composites, the lightweight composites much contain voids which are retained to reduce density during the manufacturing process. The densities of lightweight composites are lower than the densities of the materials used to build the composites. The use of lightweight composites can potentially help to save energy. For example, if the lightweight composites are used as interior materials in automobiles or aircrafts, they can help to improve the fuel efficiency. The lightweight composites made in this research aimed to be used in the automotive industry as support layers, such as headliner, door panels and cargo liners, in automotive interiors. However, the lightweight composite material should also pass the flame test and some other necessary tests before it can be used for industrial applications.

Regarding to the development of materials used as support layers, fiberglass reinforced composites were widely used as interior support layers in automobiles [1-3]. However, in last 15 years, most major automobile manufacturers tried to use lightweight composites reinforced by natural fibers, such as jute, hemp and flax, to take the place of fiberglass reinforced composites [4]. The advantages of using natural fibers were their low cost, low weight and biodegradability. However, the production of these natural fibers may decrease in the future because of the increasing global population which requires more land to grow food crops. The 
prices of these natural fibers were high compared with some biomass materials. For example, raw jute at the grade of TD3 in India was about $\$ 0.67 / \mathrm{kg}$ in January 2009 [5].

In this research, SG stems were used as reinforcements to make lightweight composites. SG is both a perennial and self-seeding crop. In addition, SG can grow on marginal lands and requires relatively moderate levels of chemical fertilizers. Generally, SG is considered as a resource-efficient, low-input energy crop from farmland [6-8]. The advantages of using SG in the composites are it is annually renewable, inexpensive, and environmentally friendly.

To the best of our knowledge, no literature was found related to lightweight composites made from long SG stems and PP nonwoven webs (a web-like material made from long PP fibers bonded together by heat treatment, neither woven nor knitted). Some references related to conventional compact composites and middle-density particle boards (with densities ranging from 0.70 to $0.90 \mathrm{~g} / \mathrm{cm}^{3}$ ) reinforced by biological materials such as wheat straw, rice straw, corn stalk, cotton stalk and switchgrass [9-35]. There are two major differences between the composites reported in the literature and the lightweight composites developed in this research. First, the biological materials in the literature were made into particles or short fibers by using mechanical and/or chemical methods. However, in this research, SG stems were simply cut and split into long length (up to $10 \mathrm{~cm}$ ), and were used directly in the composites without any chemical treatment. The simple mechanical treatments can reduce the cost for the preparation of materials. In addition, the long SG stems with large aspect ratios (length/width) can better reinforce the composites. Second, in this research, the PP webs were used as matrix materials to make composites. The use of PP webs as matrix materials has not been reported by any literature. There are two major advantages of using PP webs as matrix materials. First, the SG stems with large size can be used and distributed homogeneously in the composites. Because the SG stems can be spread on the PP webs, then the PP webs contained stems on the top can be stacked layer by layer together to make composites by compression molding. Second, the webs can potentially suit for the continuous production in the industry.

The lightweight composites, with low density of $0.47 \mathrm{~g} / \mathrm{cm}^{3}$, inevitably have some voids in the composites. The voids create defects and decrease the mechanical properties of composites. The density of lightweight composites, which is largely affected by the amount of voids, becomes an important parameter for the mechanical properties of the composites. Thus, it is not proper to compare the lightweight composites with the conventional composites or matrix materials themselves without considering the differences in density. Therefore, in this research, the properties of SG stems reinforced lightweight composites were compared with jute-PP lightweight composites with the same density.

The objectives of this research were to utilize long SG stems without any chemical treatment to make lightweight composites through a simple and cost-effective method, and to try to understand the relationship between the properties of composites and the manufacturing parameters.

\section{Experimental}

\section{Materials}

SG was obtained from a research field at the University of Nebraska-Lincoln East Campus, and SG stems were manually separated from the fully mature crops. In this research, two different stems according to the diameters were used to make composites, they were the regular SG stems (an average diameter of $3.3 \mathrm{~mm}$ with standard deviation of 0.75) and the small SG stems (an average diameter of $1.6 \mathrm{~mm}$ with standard deviation of $0.33)$ grown on the top of the plants. The tensile strength of the regular SG stem is $113.4 \pm 24.9 \mathrm{MPa}$, with Young's modulus of $15.1 \pm 2.9 \mathrm{GPa}$. The tensile strength of the small SG stem is $69.7 \pm 16.4 \mathrm{MPa}$, with Young's modulus of $8.6 \pm 1.2 \mathrm{GPa}$.

Jute fiber was supplied by Flaxcraft, Inc. (Cresskill, $\mathrm{NJ}$ ), the length of jute fiber is $5 \mathrm{~cm}$. The tensile strength of jute fiber is about $294.8 \pm 15.2 \mathrm{MPa}$, with Young's modulus of $16.9 \pm 0.8 \mathrm{GPa}$.

Nonwoven PP web was provided by Spunfab, Ltd. (Cuyahoga Falls, OH). The density of PP was $0.90 \mathrm{~g} / \mathrm{m}^{3}$ and melting temperature was $162{ }^{\circ} \mathrm{C}$. The weight/area of the PP web was $23.7 \mathrm{~g} / \mathrm{m}^{2}$. Melt Flow Index (MFI) of PP was $38 \mathrm{~g} / 10 \mathrm{~min}$ at $230^{\circ} \mathrm{C}$. PP fibers were supplied by Drake Extrusion Ltd. For the 15-denier and $84 \mathrm{~mm}$ long PP fiber, width is $45 \mu \mathrm{m}$, tensile strength is $4.0 \mathrm{~g} /$ den, melting temperature is $162{ }^{\circ} \mathrm{C}$, MFI is $20 \mathrm{~g} / 10 \mathrm{~min}$ measured at $230^{\circ} \mathrm{C}$, and crystallinity is $50 \%$.

\section{Composites Fabrication}

The weight/area of all the composites was set as $1500 \mathrm{~g} /$ $\mathrm{m}^{2}$ with an area of $25.4 \mathrm{~cm} \times 30.5 \mathrm{~cm}$. Metal spacers were used [36] to set a thickness of $3.2 \mathrm{~mm}$ during the compression molding, so the density of the composites was $0.47 \mathrm{~g} / \mathrm{cm}^{3}$. Based on the SG concentration, composite weight, and the weight/area of PP webs, the total area of required nonwoven PP webs was calculated and converted to the number of pieces of $25.4 \mathrm{~cm} \times 30.5 \mathrm{~cm}$ web. The PP webs were laid on the table and weighed SG stems were laid randomly on the webs to achieve random orientation and homogeneous distribution. The webs with SG stems on top were stacked one by one. 
Ten layers of PP webs were placed both at top and bottom in order to achieve smooth surfaces and reduce moisture absorption; the I-beam structure can also lead to increased mechanical properties. The stacked layers were placed between two aluminum sheets and pressed in a laboratory-scale "Carver" press preheated to the desired temperature.

In this method, voids were kept in the composites by controlling the thickness to make the density of the composites low. After a compression at $185^{\circ} \mathrm{C}$ for $80 \mathrm{~s}$ to make the PP melt and bond to SG stems, the press was turned off and the cooling system was turned on. When the temperature decreased to about $35^{\circ} \mathrm{C}$, the composite was removed from the press.

Each data point in the paper was the average from five tests, which were from at least three composites made at different times using the same conditions. Samples were placed in the conditioning room set at $21^{\circ} \mathrm{C}$ and $65 \%$ relative humidity for at least $48 \mathrm{~h}$ before testing.

\section{Investigation of Manufacturing Parameters}

As shown in Table 1, the effect of the concentrations of the SG stem (weight \%) on flexural, impact resistant, and tensile properties was studied. The concentrations were chosen at 40, 50, 60 and $70 \mathrm{wt} \%$. An attempt to use $30 \mathrm{wt} \%$ straw led to non-uniform mechanical properties because the stems with low weight were difficult to homogeneously cover the area of the PP webs. Thus, the lack of weight of stems and the uneven distribution of stems resulted in poor mechanical properties. On the other hand, making composites with $80 \mathrm{wt} \%$ SG stems was extremely difficult, because there were not enough webs to hold the large quantity of the stems and to prevent the stems from sliding off the edges of the composites. The length of SG stems was set at $5 \mathrm{~cm}$.

The effect of the lengths of SG stem on flexural, impact resistant and tensile properties was studied at $60 \mathrm{wt} \%$ concentration, which was determined to be the optimum condition from the first study. The lengths of SG stem were chosen at 1,5 , and $10 \mathrm{~cm}$.

The effect of the diameters of SG stem on flexural, impact resistant, and tensile properties was studied at $60 \mathrm{wt} \%$ stem and $5 \mathrm{~cm}$ stem length, which were determined to be the optimum conditions. The small SG stems (an average diameter of $1.60 \mathrm{~mm}$ with standard deviation of 0.33 ) grown on the top of SG plants were used to make composites, which were compared with the previous composites reinforced by the regular SG stems (an average diameter of $3.30 \mathrm{~mm}$ with standard deviation of 0.57 ).

For the study of the effect of surface area of stems on composite, the effect of the split configuration of SG stem on flexural, impact resistant, and tensile properties was studied at $60 \mathrm{wt} \%$ of stem and $5 \mathrm{~cm}$ stem length. Each stem was split along the longitudinal direction of stem into 2 to 4 parts using a two-roller milling machine (KICE Industries incorporation, Wichita, Kansas). The mechanical properties of composites reinforced by split SG stems were compared with the composites reinforced by the whole stems. The samples from the three types of composites reinforced by the regular SG stems, small SG stems and split SG stems respectively were used to study the sound absorption properties. And then, the mechanical properties of SG

Table 1. Experimental design

\begin{tabular}{|c|c|c|c|c|c|}
\hline & \multicolumn{5}{|c|}{ Investigation of parameters } \\
\hline & $\begin{array}{l}\text { Concentrations } \\
\text { of SG }(\%)\end{array}$ & $\begin{array}{l}\text { Lengths of } \\
\text { SG }(\mathrm{cm})\end{array}$ & $\begin{array}{l}\text { Configurations } \\
\text { of SG }\end{array}$ & $\begin{array}{l}\text { Diameters of } \\
\text { SG (mm) }\end{array}$ & $\begin{array}{l}\text { Densities of } \\
\text { composites }\left(\mathrm{g} / \mathrm{cm}^{3}\right)\end{array}$ \\
\hline $\begin{array}{l}\text { Effect of SG lengths on the mechanical } \\
\text { properties of composites }\end{array}$ & 60 & $1,5,10$ & Whole & 3.3 & 0.47 \\
\hline $\begin{array}{l}\text { The effect of the split configuration on } \\
\text { the mechanical properties of composites }\end{array}$ & 60 & 5 & $\begin{array}{l}\text { Whole and } \\
\text { Mechanically Split }\end{array}$ & 3.3 & 0.47 \\
\hline $\begin{array}{l}\text { Effect of composites densities on } \\
\text { mechanical properties of composites }\end{array}$ & 60 & 5 & Mechanically Split & 3.3 & $0.23,0.47,0.94$ \\
\hline
\end{tabular}

a. Jute-PP composites were prepared at weight/area of $1500 \mathrm{~g} / \mathrm{m}^{2}$ and thickness of $3.2 \mathrm{~mm}$, and pressed at $185{ }^{\circ} \mathrm{C}$ for $80 \mathrm{~s}$. The concentration of jute was $55 \%$. The length of jute fiber was $5 \mathrm{~cm}$ [37] 
stem-PP composites were compared with jute-PP composites of the same density and thickness as reported by Huda and Yang [37].

The relationship between the densities of composites and mechanical properties of the SG-PP and jutePP composites was studied. The density was chosen at $750 \mathrm{~g} / \mathrm{m}^{2}\left(0.24 \mathrm{~g} / \mathrm{cm}^{3}\right), 1500 \mathrm{~g} / \mathrm{m}^{2}\left(0.47 \mathrm{~g} / \mathrm{cm}^{3}\right)$ and $3000 \mathrm{~g} / \mathrm{m}^{2}\left(0.94 \mathrm{~g} / \mathrm{cm}^{3}\right)$ with the same thickness of $3.2 \mathrm{~mm}$. The SG-PP composites were made at $60 \mathrm{wt} \%$, $5 \mathrm{~cm}$ long and split SG stems, and jute-PP composites were made at $60 \mathrm{wt} \%$ of jute concentration according to the previous studies.

\section{Material Characterization}

\section{SEM Analysis}

A Hitachi model S-3000N scanning electron microscope was used for SEM imaging. The cross section of samples was coated with gold palladium and observed under the microscope at a voltage of $25 \mathrm{kV}$.

\section{Mechanical and Acoustic Testing}

An MTS QTest $\backslash 10$ tester was used for flexural testing according to procedure A of ASTM D790-03. The size of samples was $20.3 \mathrm{~cm} \times 7.6 \mathrm{~cm}$ with support length of $15.2 \mathrm{~cm}$, and the load cell was $500 \mathrm{~N}$ with the crosshead speed of $10 \mathrm{~mm} / \mathrm{min}$ for the three-point-bend tests.

Tensile tests were carried out on an MTS tester (QTest/10) according to procedure ASTM D63803. The machine was equipped with an extensometer (model MTS 634.11F-24) and a $500 \mathrm{~N}$ load cell. The samples were cut into dog-bone shape using a Type I sample template. The sample length was $165 \mathrm{~mm}$, with the width of the wide section of $19 \mathrm{~mm}$, with the width of the narrow section of $13 \mathrm{~mm}$, and with the gauge length of $115 \mathrm{~mm}$. Tensile properties of SG stems were also measured by the MTS QTest/10 tester, with a crosshead speed of $5 \mathrm{~mm} / \mathrm{min}$ and gauge length of $50 \mathrm{~mm}$.

The impact resistance test was performed in a QC-639 Universal Impact Tester by Qualitest using procedure ASTM D256-03. Sample size was $63.5 \mathrm{~mm} \times 10.2 \mathrm{~mm}$. The notch was cut perpendicular to the cross section.

The sound absorption test was carried out in a small size Brüel \& Kjær (type 4206 A) impedance tube at $0-3 \mathrm{kHz}$ frequency based on the two-microphone transfer-function method followed by procedure ASTM E1050-98. The diameter of samples was $28 \mathrm{~mm}$.

\section{Void Content Calculation}

The calculation of the void content percentage of the lightweight composites is based on the densities of composites and PP, the bulk densities of reinforcements and the weight fraction of materials. There are three types of voids in the composites: the voids between PP and reinforcements, the inner voids of PP and the inner voids of the reinforcement. The voids between PP and reinforcements are considered as defects to decrease the mechanical performance of composites, thus the volume of these voids is calculated as void content. However the volume of the other two types of voids has not been calculated, because the volume of inner voids in the molten PP is negligible $[37,38]$ and the micro inner voids in the reinforcements (SG and jute) have much little influence on the mechanical properties compared to those large voids between reinforcement and matrix material $[39,40]$. The densities of lightweight composites and PP are 0.47 and $0.90 \mathrm{~g} / \mathrm{cm}^{3}$. The bulk densities of reinforcements are tested according to glass bead displacement method [41]. However, fine sands with an average diameter of $0.34 \pm 0.11 \mathrm{~mm}$ were used as the displacement medium instead of glass beads. The calculation of void content percentage of lightweight composites is as follows:

$$
\begin{aligned}
\mathrm{VCF} & =1-\frac{\mathrm{V}_{\mathrm{PP}}}{\mathrm{V}_{\text {compo }}}-\frac{\mathrm{V}_{\text {reinf }}}{\mathrm{V}_{\text {compo }}} \\
& =1-\frac{\mathrm{W}_{\mathrm{PP}} \times \rho_{\text {compo }}}{\rho_{\mathrm{PP}}}-\frac{\mathrm{W}_{\text {reinf }} \times \rho_{\text {compo }}}{\rho_{\text {reinf }}}
\end{aligned}
$$

where VCF is the void content fraction of the composites; $\mathrm{V}_{\mathrm{PP}}$, the total volume of PP; $\mathrm{V}_{\text {reinf }}$, the total volume of reinforcements; $\mathrm{V}_{\text {compo }}$ the total volume of composites; $\rho_{\text {compo }}$ the density of composites; $\rho_{\mathrm{PP}}$ the density of PP; $\rho_{\text {reinf }}$ the bulk density of reinforcements; $\mathrm{W}_{\mathrm{pp}}$, the weight fraction of $\mathrm{PP}$ in the composites; and $\mathrm{W}_{\text {reinf }}^{\mathrm{pp}}$ the weight fraction of reinforcements in the composites.

\section{Statistics Method}

Fisher's Least Significant difference (LSD) was used to test the effect of various conditions on the properties of composites using SAS (SAS Institute Inc., NC). The pvalue was set at 0.05 .

\section{Results and Discussion}

\section{The Effect of Stem Concentrations on the Mechanical Properties of SG-PP Composites}

As demonstrated in Figure 1, flexural strength, modulus of elasticity, impact resistance properties and Young's modulus increased significantly ( $\mathrm{p}$ value $<0.05$ ) from 50 to $60 \%$ of SG stem concentration, and then decreased significantly from 60 to $70 \%$ of the stem concentration. 


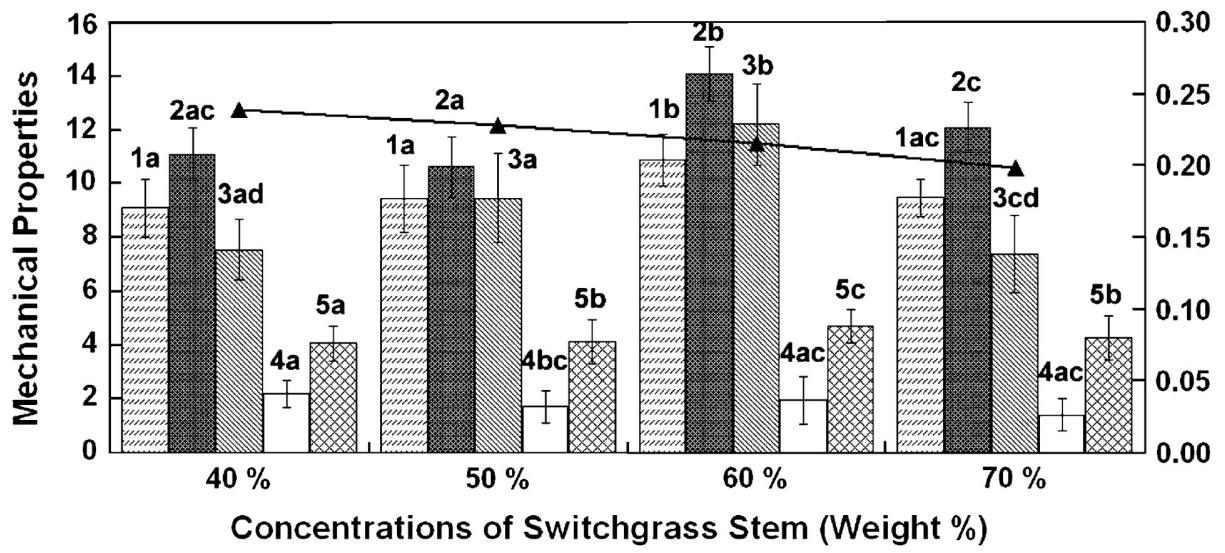

\begin{tabular}{|ll|}
\hline Flexural Strength $(\mathrm{MPa})$ & Modulus of Elasticity (100 MPa) \\
Impact Resistance $\left(10 \mathrm{~J} \mathrm{~m}^{-1}\right)$ & $\square$ Tensile Strength (MPa) \\
— Void Content Percentage \\
\hline
\end{tabular}

Figure 1. The effects of SG stem concentrations (40,50, 60 and 70\%) on flexural strength, modulus of elasticity, impact resistance, tensile strength and Young's modulus of SG-PP composites. Composites were fixed at weight/area of $1500 \mathrm{~g} / \mathrm{m}^{2}$ and thickness of $3.2 \mathrm{~mm}$, and pressed at $185^{\circ} \mathrm{C}$ for $80 \mathrm{~s}$. SG stems were $5 \mathrm{~cm}$ long with regular-sized and whole configuration. $1,2,3,4,5$ : If data points had the same number, they represented the same mechanical property. $\mathbf{a}, \mathbf{b}, \mathbf{c}$, d: If any two data points of the same mechanical property had totally different letters, the two data points were statistically different.

However, the tensile strength did not show significant differences among the concentrations of 50,60 and $70 \%$.

As shown in Figure 1, the void content percentages of composites showed a decrease from 23.9 to $19.8 \%$ as the concentration of SG increased from 40 to $70 \%$. The bulk densities of SG were tested to be $0.42 \pm 0.01 \mathrm{~g} / \mathrm{cm}^{3}$ at $40 \%$ of SG concentration, $0.46 \pm 0.02 \mathrm{~g} / \mathrm{cm}^{3}$ at $50 \%$ of SG concentration, $0.49 \pm 0.01 \mathrm{~g} / \mathrm{cm}^{3}$ at $60 \%$ of SG concentration and $0.51 \pm 0.02 \mathrm{~g} / \mathrm{cm}^{3}$ at $70 \%$ of SG concentration. The increased bulk densities of SG are because SG was compressed more tightly at higher concentrations than lower concentration of SG.

When the concentrations of SG stems are low, at about $40 \%$, there are not enough stems to reinforce the polymer matrix. In addition, the small amount of SG stems can only cover limited area on the PP webs and cannot be compressed completely. As demonstrated by the SEM image in Figure 2a, the visible voids were formed within the SG stems. The void content percentage of composites at $40 \%$ of SG also shows higher value than the composites with higher concentrations of SG. The voids in the composites lead to poor mechanical properties. With the increase of SG concentration, there are more SG stems to reinforce the composites. Meanwhile, the SG stems can cover large areas on the webs and occupy more volume in the composites because of the lower density of SG than PP, and results in a decrease of the amount of voids in the composites. As shown in Figure $2 \mathrm{~b}$ and $\mathrm{c}$, the amount of voids decreased and the SG stems were compressed tightly due to the high concentrations of SG stems. Both the increased concentration of SG stems and decreased voids lead to the improved properties. However, as the stem concentration increases, as high as $70 \%$, the flexural properties, impact resistance and Young's modulus decrease. This is because the density of the composites is fixed. The increase of SG concentration must decrease the weight percentage of the PP webs. These changes result in a decreased interaction between SG stems and PP webs at higher concentrations of SG stems. The poor interaction, because of the lack of matrix materials, results in the decrease of mechanical properties. The tensile strength did not show significant difference among concentrations because of the poor bond between PP and non-chemical treated SG.

\section{The Effect of Stem Lengths on the Mechanical Properties of SG-PP Composites}

As shown in Figure 3, the flexural strength, modulus of elasticity, impact resistance and Young's modulus first increased significantly with the increase of stem lengths from 1 to $5 \mathrm{~cm}$ and then decreased significantly with the increase of the length from 5 to $10 \mathrm{~cm}$. The tensile strength did not show significant differences among the lengths of 1,5 , and $10 \mathrm{~cm}$.

The increased length with unchanged width of the stem is directly related to the increase of the aspect ratio of the stem. Although the aspect ratio is usually applicable for much finer things such as fibers, the explanation using the theory of aspect ratio also suit for the discussion of the configurations of stems. The aspect ratio of the reinforcing materials is a critical factor in determining mechanical properties of composites [38]. The large 
Figure 2. SEM images of the cross sections of SG-PP composites. Composites were fixed at weight/area of $1500 \mathrm{~g} / \mathrm{m}^{2}$ and thickness of $3.2 \mathrm{~mm}$, and pressed at $185^{\circ} \mathrm{C}$ for $80 \mathrm{~s}$. SG stems were $5 \mathrm{~cm}$ long with regularsized and whole configuration. a: $40 w t \%, b: 60 w t \%, c: 70 w t \%$, bar $=1 \mathrm{~mm}$.
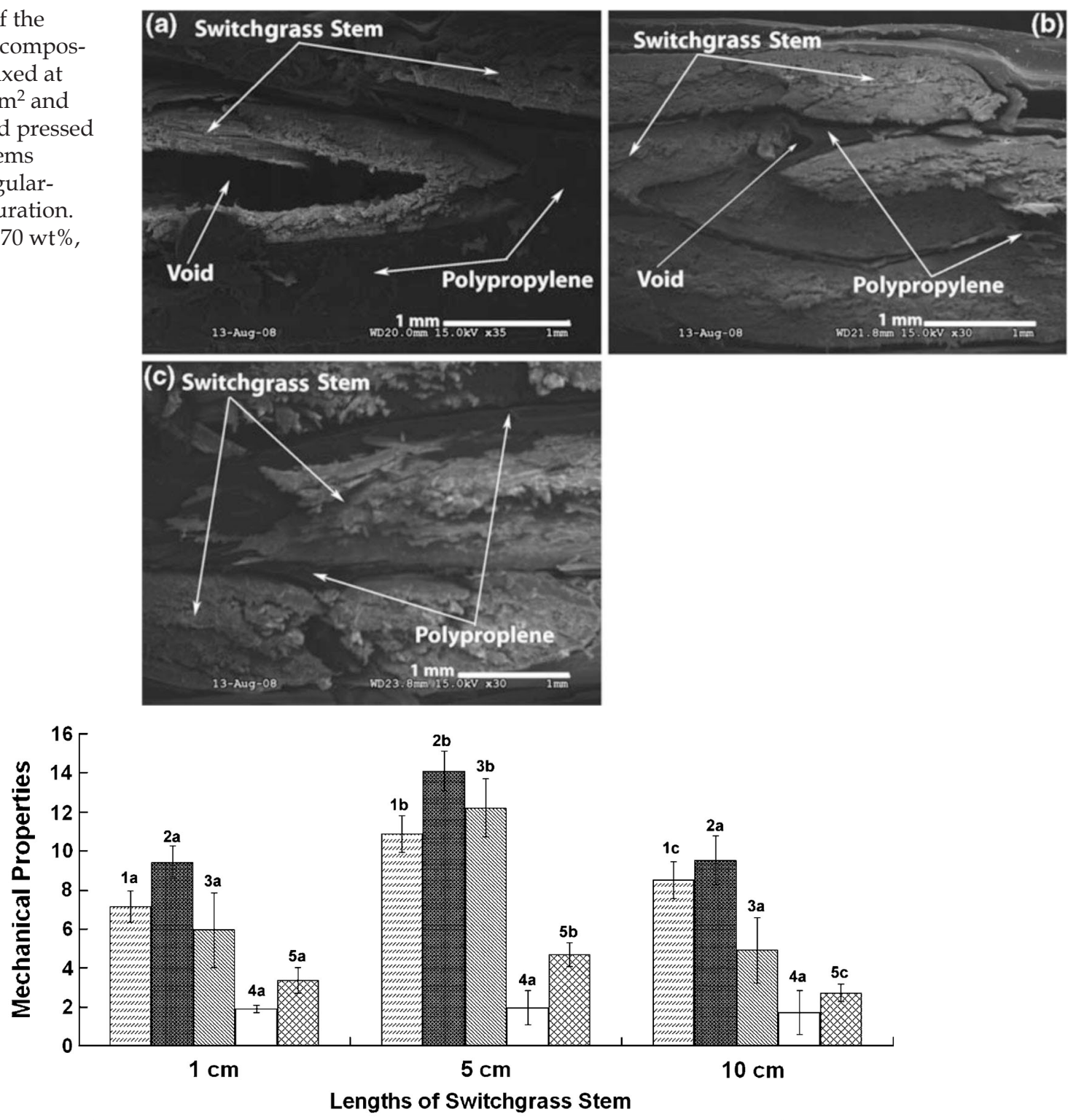

Figure 3. The effects of lengths of regular SG stem $(1,5$ and $10 \mathrm{~cm})$ on flexural strength, modulus of elasticity, impact resistance, tensile strength and Young's modulus of SG-PP composites. Composites were fixed at weight/area of $1500 \mathrm{~g} / \mathrm{m}^{2}$ and thickness of $3.2 \mathrm{~mm}$, and pressed at $185^{\circ} \mathrm{C}$ for $80 \mathrm{~s}$. The concentration of SG stems was $60 \% .1,2,3,4$, 5: if data points had the same number, they represented the same mechanical property. $\mathbf{a}, \mathbf{b}$, c: If any two data points of the same mechanical property had totally different letters, the two data points were statistically different.

aspect ratio can promote the transfer of stress from reinforcements to matrix materials, and finally results in the increase in mechanical properties. However, when the lengths of SG stem further increased from 5 to $10 \mathrm{~cm}$, the distribution of the stems on PP webs became less homogeneous due to the larger size of the stems. The lessened homogeneity leads to an increase in the amounts of defects, and results in the reduction of the mechanical properties.

\section{The Effect of Stem Diameters on the Mechanical Properties of SG-PP Composites}

Compared with the composites reinforced by the regular SG stems, the composites reinforced by the small SG stems have significantly higher modulus of elasticity and tensile strength, as shown in Figure 4. Although the tensile properties of the small SG stem are significantly worse than the regular SG stem (the datum for the stem 


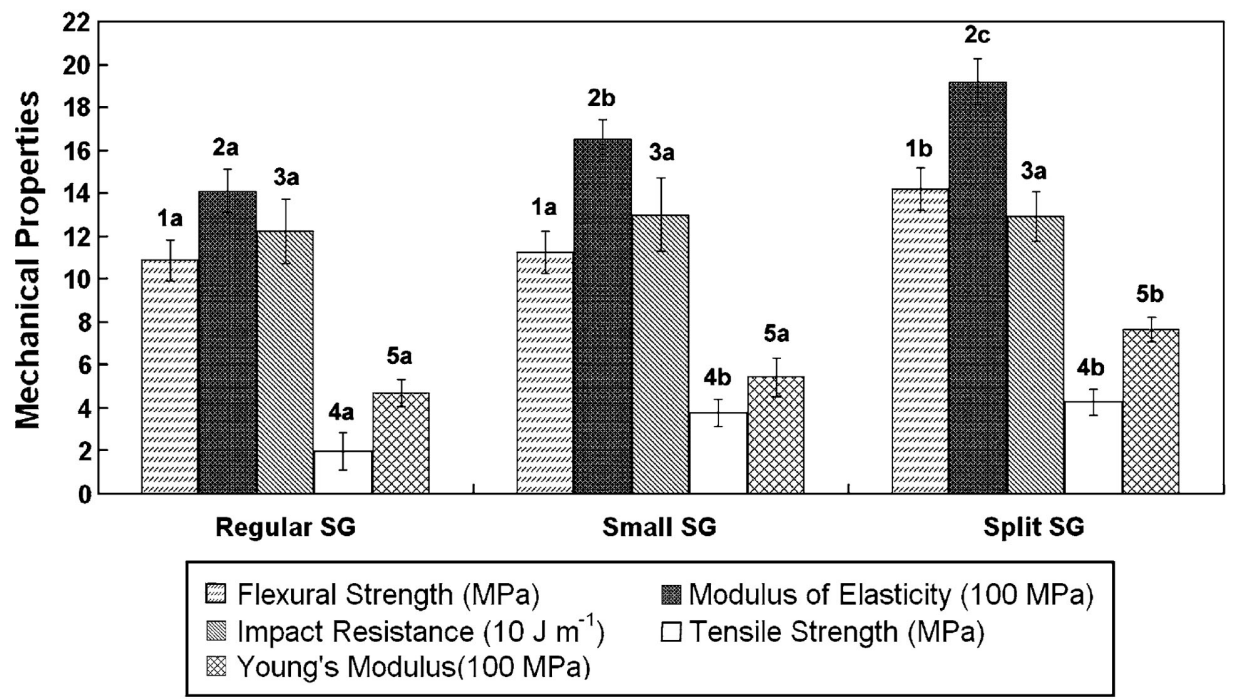

Figure 4. The effects of the split configuration and diameter of SG stem on flexural, impact resistance properties and tensile properties of SG-PP composites. Composites were fixed at weight/area of $1500 \mathrm{~g} / \mathrm{m}^{2}$ and thickness of $3.2 \mathrm{~mm}$, and pressed at $185^{\circ} \mathrm{C}$ for $80 \mathrm{~s}$. The concentration of SG stem was $60 \%$. The length of the SG stem was $5 \mathrm{~cm} . \mathbf{1 , 2 , 3 , 4 , 5 :}$ if data points had the same number, they represented the same mechanical property. $\mathbf{a}, \mathbf{b}, \mathbf{c}$ : If any two data points of the same mechanical property had totally different letters, the two data points were statistically different.

properties were presented at the experimental section), the aspect ratio and bulk density play more important roles in determining the properties of the composites. The decreased diameter with unchanged length of the stem leads to an increased aspect ratio which helps to improve the transfer of stress between the stems and the PP to achieve higher properties of composites. The lower bulk density of the small SG stem $(0.42 \pm 0.03 \mathrm{~g} /$ $\mathrm{cm}^{3}$ at $60 \%$ of SG concentration) than that of the regular stem $\left(0.49 \pm 0.01 \mathrm{~g} / \mathrm{cm}^{3}\right.$ at $60 \%$ of SG concentration) allows the stems to be used in larger volume and cover more area on the webs to decrease voids and improve the properties. However, other mechanical properties of the composites reinforced by the small SG stems do not show significant differences from the composites using regular SG stems.

\section{The Effect of the Split Configuration on the Mechanical Properties of SG-PP Composites}

As shown in Figure 4, the flexural strength, modulus of elasticity, tensile strength and Young's modulus of the composites reinforced by the split SG stems were significantly higher than those of the composites reinforced by the regular SG stems. The regular SG stems (round with a hollow center) were split into two to four parts in order to increase the aspect ratio and enlarge the surface area. The opened inner and rough surface can improve the adhesive property between the stems and the matrix materials. The increased aspect ratio also leads to the improved mechanical properties.

\section{Comparison of the Mechanical Properties Between SG-PP and Jute-PP Composites}

As shown in Table 2, composites from mechanically split SG stem had nearly $56 \%$ higher flexural strength, $19 \%$ higher modulus of elasticity, 15\% higher impact resistance, 63\% higher Young's modulus, and 52\% lower tensile strength compared with jute composites based on the data of jute-PP composites reported by Huda and Yang [37]. However, the tensile properties of SG stems were much worse than that of jute fiber. The regular SG stem had $113.4 \mathrm{MPa}$ tenacity, $0.9 \%$ breaking elongation,

Table 2. Comparison of mechanical properties of composites from mechanically split SG stem and jute

\begin{tabular}{llllll}
\hline Composites & FS (MPa) & MOE (GPa) & IR (J/m) & TS (MPa) & YM (MPa) \\
\hline Mechanically Split SG Stem-PP & $14.2 \pm 1.0$ & $1.9 \pm 1.0$ & $129.4 \pm 11.6$ & $4.3 \pm 0.6$ & $763.6 \pm 58.4$ \\
Natural Jute-PPa & $9.1 \pm 0.4$ & $1.6 \pm 1.0$ & $112.3 \pm 8.6$ & $8.9 \pm 0.8$ & $469.3 \pm 30.1$ \\
\hline
\end{tabular}

Both composites were fixed at weight/area of $1500 \mathrm{~g} / \mathrm{m}^{2}$ and thickness of $3.2 \mathrm{~mm}\left(0.47 \mathrm{~g} / \mathrm{cm}^{3}\right)$, and pressed at $185{ }^{\circ} \mathrm{C}$ for $80 \mathrm{~s}$. The concentration of SG stem and jute was $60 \%$. The length of the split SG stem and jute fiber was $5 \mathrm{~cm}$

FS = flexural strength, $\mathrm{MOE}=$ modulus of elasticity, IR = impact resistance, $\mathrm{TS}=$ tensile strength, YM = Young's modulus a. Jute data is from Huda and Yang [37] 
and 15.1 GPa modulus compared with $295 \mathrm{MPa}$ tenacity, $1.1 \%$ breaking elongation, and $16.9 \mathrm{GPa}$ modulus for jute [38]. The reasons for the better mechanical properties, except the tensile strength, of composites reinforced by SG stems are mainly because of the low bulk density of SG stem. The bulk density of the stem is $0.49 \pm 0.01 \mathrm{~g} /$ $\mathrm{cm}^{3}$ at $60 \%$ of SG concentration. That is lower than the bulk density of jute fiber $\left(1.02 \pm 0.04 \mathrm{~g} / \mathrm{cm}^{3}\right)$. The void content percentage of SG-PP composites at $60 \%$ of SG concentration is $21.6 \%$, which is much lower than the void content percentage of jute-PP composites (51.5\% of void content). With the same weight of the reinforcing material in the composites, the lower bulk density of the stem allows the SG stems to be used in a higher volume that leads the stems to cover a larger area on the webs and to be packed very tightly in composites. During compression molding, the voids between stems and PP are reduced, due to the highly packed SG stems, to improve the mechanical properties.

\section{Effect of Composites Densities on Mechanical Properties of SG-PP and Jute-PP Composites}

For lightweight composites, the density of composites plays a critical role in determining the mechanical properties of the composites. When the density of composites is low, there are many voids in the composites. These voids create defects and decrease the mechanical properties of composites. The increasing of the density of composites leads to the increasing of the weight of both reinforcing materials and matrix materials, as well as the decreasing of the amount of voids. These changes lead to better mechanical properties than the composites at low density. As shown in Table 3, both mechanical properties of SG stem-PP and jute-PP composites increase greatly as the densities increase. The relationship between densities $\left(750,1500\right.$ and $3000 \mathrm{~g} / \mathrm{m}^{2}$ with fixed thickness of $3.2 \mathrm{~mm}$ ) and mechanical properties was found to be linear with $R^{2}$ higher than 0.92 .

\section{Effect of the Whole and Split Configurations of SG Stems on Sound Absorption Properties of SG-PP Composites}

As seen in Figure 5, composites from the regular SG stem have slightly higher sound absorption coefficients than composites from the small SG stem and split SG stem. The composites reinforced by the split SG stems have the lowest sound absorption coefficients in the comparison. This is because the split SG stems with larger surface area can cover more area in the composites, and are highly packed in the composites and leave a few amounts of micro voids in the composites. The micro voids can help to absorb the energy of sound waves

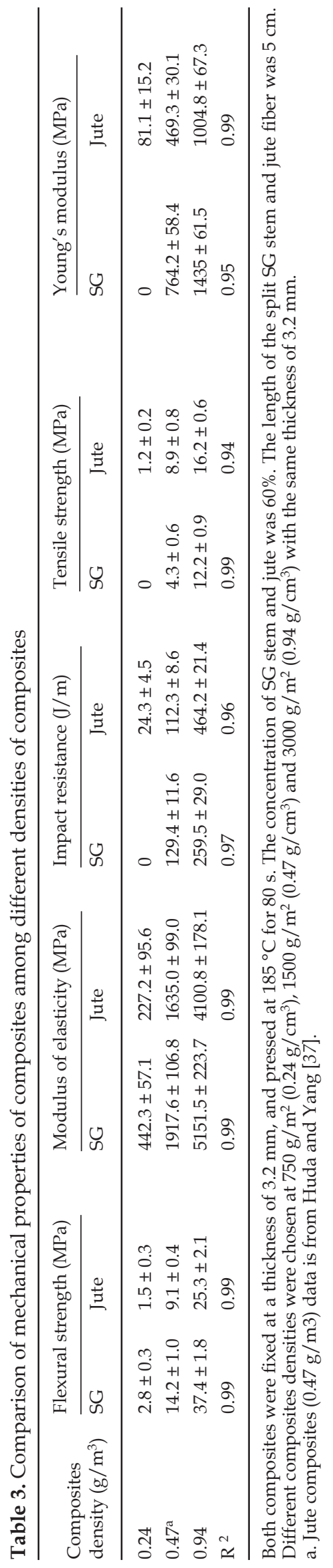




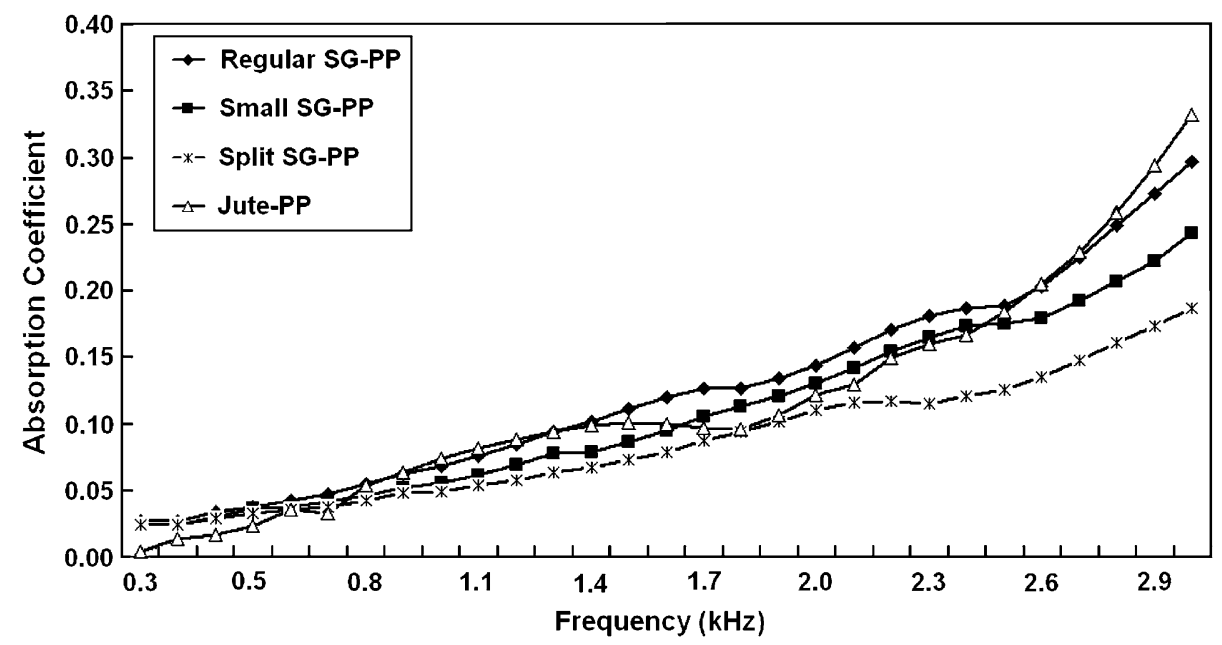

Figure 5. The effects of the regular SG stem (3.31 mm average in diameter), small SG stem (1.61 mm average in diameter) and split SG stem on sound absorption properties of SG-PP composites. The sound absorption of jutePP composites was compared. Composites were fixed at weight/area of $1500 \mathrm{~g} / \mathrm{m}^{2}$ and thickness of $3.2 \mathrm{~mm}$, and pressed at $185^{\circ} \mathrm{C}$ for $80 \mathrm{~s}$. The concentration of reinforcements was $60 \%$. The length of SG stem or jute fiber was $5 \mathrm{~cm}$.

when sound waves travel through different phases. Thus, the lower micro-voids content of composites reinforced by split SG stem leads to lower sound absorption abilities compared to the composites reinforced by the regular and small SG stems. Compared to jutePP composites, the composites reinforced by the whole SG stems (the regular and small SG stems) have similar sound absorption properties, while the composites reinforced by the split SG stems have slightly worse property than jute-PP composites. However, good sound absorption property at low frequency (below $1.5 \mathrm{kHz}$ ) is desired for automotive composites because this frequency zone corresponds with noise from tires, the running engine, road, conversations, and wind. Thus SG-PP composites have similar sound absorption behavior as the jute-PP composites.

\section{Conclusions}

In this research, a newly developed method was applied to make lightweight composites from long SG stems and PP nonwoven webs. When the manufacturing parameters are set at $60 \%$ concentration of SG stems and $5 \mathrm{~cm}$ long with split configuration of stems, the SGPP composites showed the best mechanical properties among the conditions studied during the compression molding at $185^{\circ} \mathrm{C}$ for $80 \mathrm{~s}$. Composites from mechanically split SG stem have $56 \%$ higher flexural strength, $19 \%$ higher modulus of elasticity, 15\% higher impact resistance, $63 \%$ higher Young's modulus and 52\% lower tensile strength and similar sound absorption property compared with jute-PP composites. Although the tensile properties of SG stem are much worse than jute fi- ber, SG stems with low bulk density are found to better reinforce the lightweight composites. Except for the tensile strength, the superior mechanical properties of SG-PP compared with jute-PP composites, provide an opportunity for applications of SG composites in automotive interiors where composites reinforced by natural fibers are currently being used as support layers, and in the construction industry with the products such as ceiling tiles and office panels.

Acknowledgments - The authors are grateful for financial supports from the University of Nebraska-Lincoln Agricultural Research Division, Hatch Act and USDA Multistate Research Project S-1026, and the John and Louise Skala Fellowship. We thank Narendra Reddy of the University of Nebraska-Lincoln for support in various fashions.

\section{References}

1. Mohanty AK, Misra M, Hinrichsen G (2000) Macromol Mater Eng 276(277):1

2. Mueller DH, Krobjilowski A (2003) J Ind Text 33:111

3. Sink SE (2005) Special report: cars made of plants? Online news release, accessed Dec. 13, 2005; http://www.edmunds.com/advice/specialreports/articles/105341/article.html

4. Ellison GC, McNaught R (2008) Research \& development report-the use of natural fibres in nonwoven structures for applications as automotive component substrates; accessed April 19, 2008; http://www.defra.gov.uk/farm/crops/industrial/research/reports/Rdrep10.pdf

5. Worldjute; accessed May 31, 2008; http://www.worldjute. com/jute_prices/prices_index.html 
6. Goel K, Radiotis T, Eisner R, Sherson G, Li J (2000) Pulp Pap Can 101:41

7. Law KN, Kokta BV, Mao CB (2001) Bioresour Technol 77:1

8. Reddy N, Yang Y (2007) Biotechnol Bioeng 97:1021

9. Alemdar A, Sain M (2008) Compos Sci Technol 68:557

10. Avella M, Bozzi C, Erba R, Focher B, Marzetti A, Martuscelli E (1995) Die Angewandte Makromolekulare chemie 233:149

11. Buzarovska A, Bogoeva-Gaceva G, Grozdanov A, Avella M, Gentile G, Errico M (2008) Aust J Crop Sci 1:37

12. Digabel FL, Boquillon N, Dole P, Monties B, Averous L (2004) J Appl Polym Sci 93:428

13. Frounchi M, Dadbin S, Jahanbakhsh J, Janat-Alipour M (2007) Polym Polym Compos 15:619

14. Han G (2001) Wood Res 88:19

15. Hassan ML, Nada MA (2003) J Appl Polym Sci 87:653

16. Hervillard T, Cao Q, Laborie M (2007) BioResearch 2:148

17. Hornsby PR, Hinrichsen E, Tarverdi K (1997) J Mater Sci 32:443

18. Hornsby PR, Hinrichsen E, Tarverdi K (1997) J Mater Sci 32:1009

19. Huda S, Yang Y (2008) Compos Sci Technol 68:790

20. Huda S, Yang Y (2009) J Polym Environ 17:131

21. Mengeloglu F, Karakus K (2008) Sensors 8:500

22. Micusik M, Omastova M, Nogellova Z, Fedorko P, Olejnikova K, Trchova M, Chodak I (2006) Eur Polym J 42:2379

23. Mishra S, Patil YP (2004) Mol Cryst Liq Cryst 418:101
24. Mo X, Wang D, Sun XS (2005) Natural fibers, biopolymers, and biocomposites. CRC Press, New York

25. Panthapulakkal S, Sain M (2006) J Polym Environ 14:265

26. Panthapulakkal S, Sain M, Law S (2005) Polym Int 54:137

27. Panthapulakkal S, Law S, Sain M (2005) J Thermoplast Compos Mater 18:445

28. Panthapulakkal S, Zereshkian A, Sain M (2006) Bioresour Technol 97:265

29. Schirp A, Loge F, Aust S, Swaner P, Turner G, Wolcott M (2006) J Appl Polym Sci 102:5191

30. Schirp A, Loge F, Englund K, Wolcott M, Hess J, Houghton T, Lacey J, Thompson D (2006) Forest Prod J 56:90

31. Shakeri AR, Hashemi SA (2004) Polym Polym Compos 12:449

32. Yao F, Wu Q, Lei Y, Xu Y (2008) Ind Crops Prod 28:63

33. Ye X, Julson J, Kuo M, Myers D (2005) Trans ASABE 48:1629

34. Ye X, Julson J, Kuo M, Womac A, Myers D (2007) Bioresour Technol 98:1077

35. Zhang Y, Lu X, Pizzi A, Delmotte L (2003) Holz als Rohund Werkstoff 61:49

36. Wolcott M (2003) For Prod J 35:25

37. Huda S, Yang Y (2009) Ind Crop Prod 30:17

38. Huda S, Yang Y (2008) Macromol Mater Eng 293:235

39. Zou Y, Huda S, Yang Y (2010) Bioresour Technol 101:2026

40. Zou Y, Reddy N, Yang Y (2010) J Appl Polym Sci 116:2366

41. Bhatnagar S, Hanna MA (1995) Trans ASABE 38:567 